\title{
$\left[{ }^{18}\right.$ F]FDG-PET Evaluation of Spinal Pathology in Patients in Oncology: Pearls and Pitfalls for the Neuroradiologist
}

\author{
(D) P.Y. Patel, (1)I. Dalal, and (D)B. Griffith
}

\begin{abstract}
SUMMARY: $\left[{ }^{18}\right.$ F]FDG-PET is a widely used technique for specific evaluation of disease and treatment response in oncology. However, the principles behind $\left[{ }^{18}\right.$ F]FDG-PET imaging allow a wide-ranging array of benign and malignant pathologies to be identified on both initial and routine surveillance imaging. This is important for clinicians and radiologists, alike, in that effective and accurate evaluation of malignancy and metastatic disease, specifically involving the spine and central nervous system, is crucial. In this article, we review the normal and posttherapy appearance of the spine on $\left[{ }^{18} \mathrm{~F}\right] \mathrm{FDG}-\mathrm{PET}$, the various types and patterns of metastatic disease that involve the spine and spinal cord, and, finally, important spinal pathologies that may mimic malignancy on $\left[{ }^{18} \mathrm{~F}\right] \mathrm{FDG}-\mathrm{PET}$.
\end{abstract}

ABBREVIATIONS: G-CSF = granulocyte colony-stimulating factors; ISCM $=$ intramedullary spinal cord metastasis; SUV $=$ standard uptake value; SUV max $=$ maximum standard uptake value

S ince its inception in the mid-1970s, $\left[{ }^{18} \mathrm{~F}\right]$ FDG-PET has grown into a multifaceted tool with applications not only in cancer imaging but in neurologic disorders, infection, inflammation, and cardiac imaging. ${ }^{1}$ As one of the most quantitative imaging techniques available for assessing metastatic disease, $\left[{ }^{18} \mathrm{~F}\right] \mathrm{FDG}-$ PET/CT has become an essential imaging tool in the diagnosis, staging, and management of cancer and cancer-related disease during the past two decades. ${ }^{1}$ Although metastatic disease can occur anywhere, the spine is of particular importance, not only because it is the third most frequent site of distant metastatic disease but also because many nonmalignant processes, some of which can appear nearly identical to metastatic foci on $\left[{ }^{18} \mathrm{~F}\right]$ FDG-PET, are frequently identified involving the spine during the course of a patient's routine oncologic work-up. ${ }^{2}$

While MR imaging is the most crucial imaging technique used to assess spinal metastatic disease, various metastatic disease patterns have been demonstrated on $\left[{ }^{18} \mathrm{~F}\right]$ FDG-PET, which can help in disease localization and assessment. ${ }^{2,3}$ Understanding both the benefits and pitfalls of $\left[{ }^{18} \mathrm{~F}\right] \mathrm{FDG}$-PET in evaluating the spine is important, given the frequent use of PET and PET/CT in both oncologic work-up and surveillance. This review will discuss

Received June 22, 2021; accepted after revision August 4

From the Department of Radiology, Henry Ford Hospital, Detroit, Michigan.

Please address correspondence to Brent Griffith, MD, Department of Radiology, K3, Henry Ford Hospital, 2799 West Grand Blvd, Detroit, MI 48202; e-mail: brentg@rad.hfh.edu; @BrentDGriffith

- Indicates open access to non-subscribers at www.ajnr.org

http://dx.doi.org/10.3174/ajnr.A7308 general $\left[{ }^{18} \mathrm{~F}\right] \mathrm{FDG}-\mathrm{PET}$ and, most important, nonmetastatic pitfalls that may appear similar on standard $\left[{ }^{18} \mathrm{~F}\right] \mathrm{FDG}-\mathrm{PET}$.

\section{Normal Distribution of $\left[{ }^{18}\right.$ F]FDG in the Spine}

In the assessment for metastatic disease in the spine, recognition of the normal or physiologic appearance of $\left[{ }^{18} \mathrm{~F}\right] \mathrm{FDG}-\mathrm{PET}$ is essential. Because $\left[{ }^{18} \mathrm{~F}\right] \mathrm{FDG}$ uptake in PET reflects tissue levels of cellular glucose metabolism, normal anatomic structures in the spine can demonstrate variable degrees of hypermetabolic uptake. Specifically, relative increases in physiologic $\left[{ }^{18} \mathrm{~F}\right] \mathrm{FDG}$ uptake have been demonstrated in the spinal cord at the T11 and T12 levels and, to a lesser degree, at the C4 level (Fig 1). ${ }^{4-6}$ Additionally, slight relative physiologic uptake within the cord has also been noted at the level of the atlas. ${ }^{7}$ While not definitively explained, it is theorized that the increased uptake in the lower thoracic cord is due to inadequate clearance of the radiotracer from the artery of Adamkiewicz, which originates from the aorta between T9 and T11, and/or due to the relative increased cross-sectional area of the spinal cord at the midcervical and lower thoracic levels with an associated increased ratio of gray matter. ${ }^{4,5,7}$

Relative changes in physiologic uptake can also be noted within the vertebral bodies, with background marrow uptake typically having a maximum standard uptake value $\left(S_{U} V_{\max }\right)$ of $<3{ }^{8}$ Peak physiologic radiotracer uptake has been noted within the lower thoracic vertebral bodies, typically between T8 and T11, though standard uptake values (SUVs) are usually below those of the liver. ${ }^{8,9}$ Additionally, although subtle, SUVs typically demonstrate a gradual decrease both cranially and caudally. ${ }^{6,9}$ 


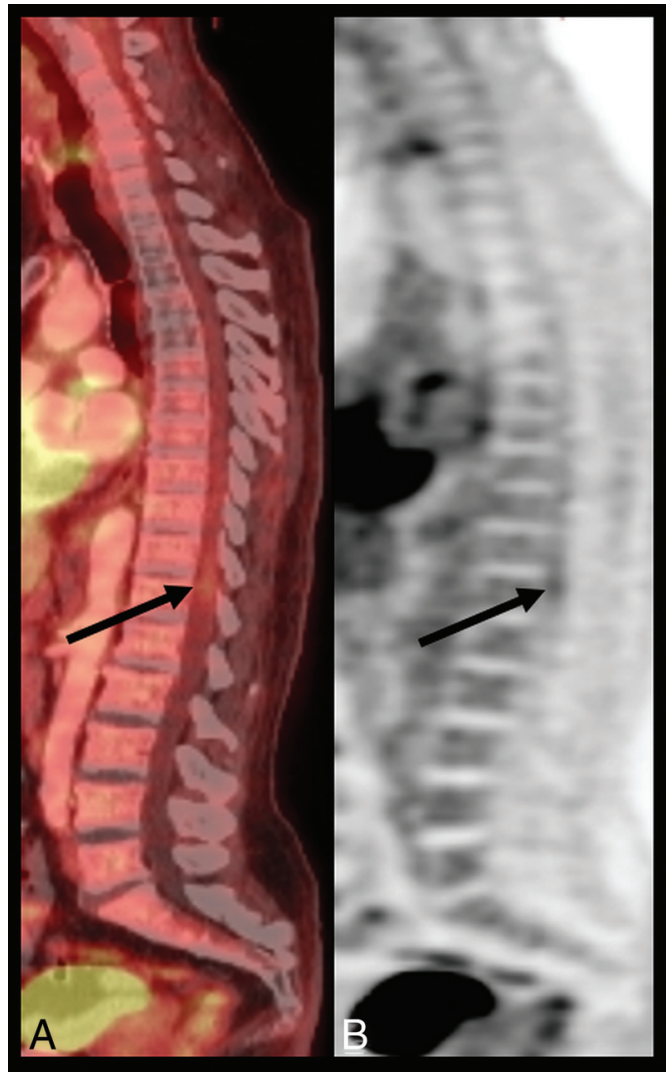

FIG 1. A 59-year-old man with lung cancer without metastatic disease. Sagittal fused $(A)$ and AC PET $(B)$ images demonstrate physiologic $\left[{ }^{18} \mathrm{~F}\right]$ FDG uptake throughout the spine as well as focal physiologic $\left[{ }^{18} \mathrm{~F}\right] \mathrm{FDG}$ spinal cord uptake at T1-T12 (arrows). Absent uptake in the midthoracic spine is related to previous radiation therapy. Fused indicates fused PET and CT image; AC, attenuation-corrected.

Because this increased uptake often appears as focal areas within the marrow and can be misleading on axial images, it is important to correlate with the sagittal and coronal planes. Because $\left[{ }^{18} \mathrm{~F}\right]$ FDG uptake is dependent on active hematopoietic marrowred marrow, studies have shown a gradual decrease in osseous $\left[{ }^{18} \mathrm{~F}\right] \mathrm{FDG}$ uptake with increasing age as red marrow is replaced by yellow marrow. ${ }^{8}$

\section{Posttherapy Changes of the Spine}

Many cancer therapies play an important role in the oncologic application of $\left[{ }^{18} \mathrm{~F}\right]$ FDG-PET, with two of the most common being granulocyte colony-stimulating factors (G-CSF) and radiation therapy. G-CSF is a glycoprotein hormone used to treat chemotherapy-induced neutropenia and reduce infection severity by stimulating hematopoietic progenitors. ${ }^{10}$ Diffusely increased, homogeneous radiotracer uptake is identified throughout the bone marrow both during and after G-CSF administration in up to $87 \%$ of patients. ${ }^{10,11}$ Given this diffuse marrow uptake, both bone metastases and benign bone lesions may be obscured or appear as photopenic defects due to the relative hyperplastic bone marrow (Fig 2). ${ }^{11}$ Although the optimal timeframe for follow-up PET/CT in the setting of G-CSF therapy has not been determined, studies have shown that bone marrow $\left[{ }^{18} \mathrm{~F}\right] \mathrm{FDG}$ uptake can remain elevated for up to 1 month after administration of G-CSF, with return to plateau times ranging from 10 days to 1 month. ${ }^{11,12}$

Radiation therapy can also have considerable effects on normal tissue, especially hematopoietic bone marrow. Specifically, radiation therapy can cause immediate avid $\left[{ }^{18} \mathrm{~F}\right] \mathrm{FDG}$ uptake due to local postradiation inflammation. ${ }^{10}$ Therefore, $\left[{ }^{18} \mathrm{~F}\right] \mathrm{FDG}-\mathrm{PET}$ is typically performed 8-12 weeks after completion of radiation therapy for better assessment of the treatment response. ${ }^{13}$ In the subacute and chronic stages after radiation therapy, treated areas of bone marrow
typically appear as photopenic regions,

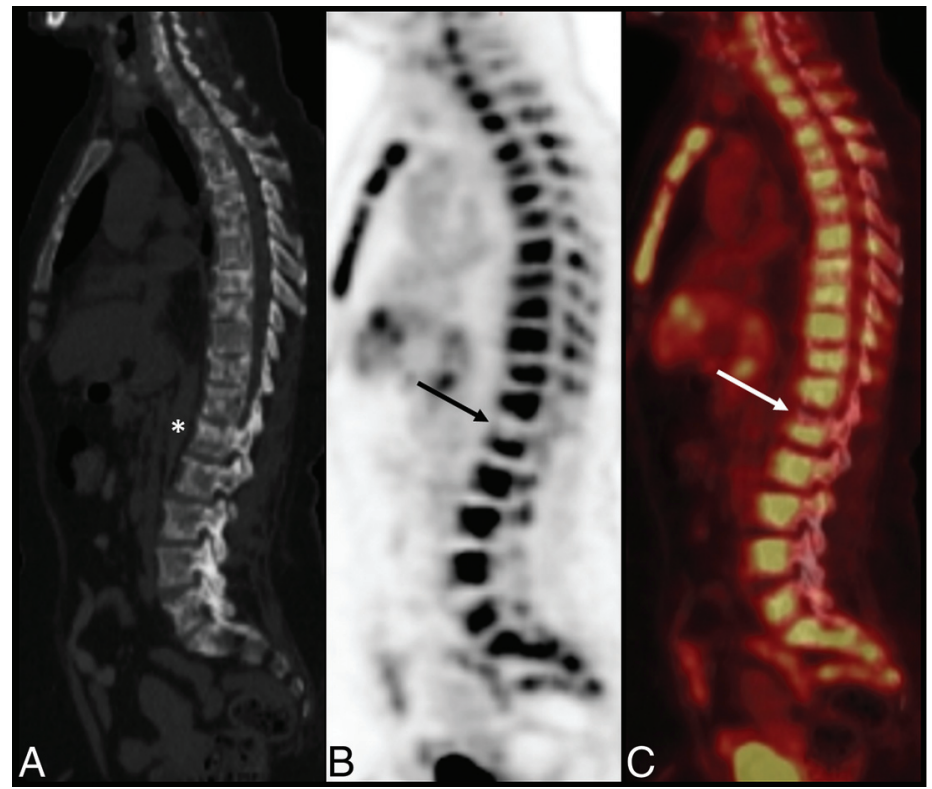

FIG 2. A 62-year-old woman with breast cancer. Sagittal CT (A), AC PET (B), and fused $(C)$ images demonstrate a sclerotic (asterisk) and photopenic region (solid arrows) in the Ll vertebral body consistent with a site of treated metastasis. Note the diffusely increased radiotracer uptake through the remaining axial skeleton, which obscures multilevel osseous metastases seen on CT. Fused indicates fused PET and CT image; AC, attenuation-corrected. matching the geographic radiation field (Fig 3). ${ }^{10,11}$ Some patients have experienced $\left[{ }^{18} \mathrm{~F}\right] \mathrm{FDG}$ uptake in irradiated bone marrow gradually decreasing below baseline levels as early as 28 days after therapy. ${ }^{14}$

\section{Metastatic Disease of the Spine}

The spine is the third most common site for distant metastatic disease after the lung and liver and is the most common site for osseous metastases, with approximately $50 \%-70 \%$ of patients with systemic cancer having spinal involvement. ${ }^{2}$ Involvement of the spine in the setting of cancer can be divided into distant metastases, either through hematogenous or lymphatic spread or by extension from surrounding tissues, including by local invasion or perineural spread. ${ }^{2}$ While the conventional oncologic work-up for spinal metastatic disease involves detailed MR imaging evaluation, $\left[{ }^{18} \mathrm{~F}\right] \mathrm{FDG}-\mathrm{PET}$ is 


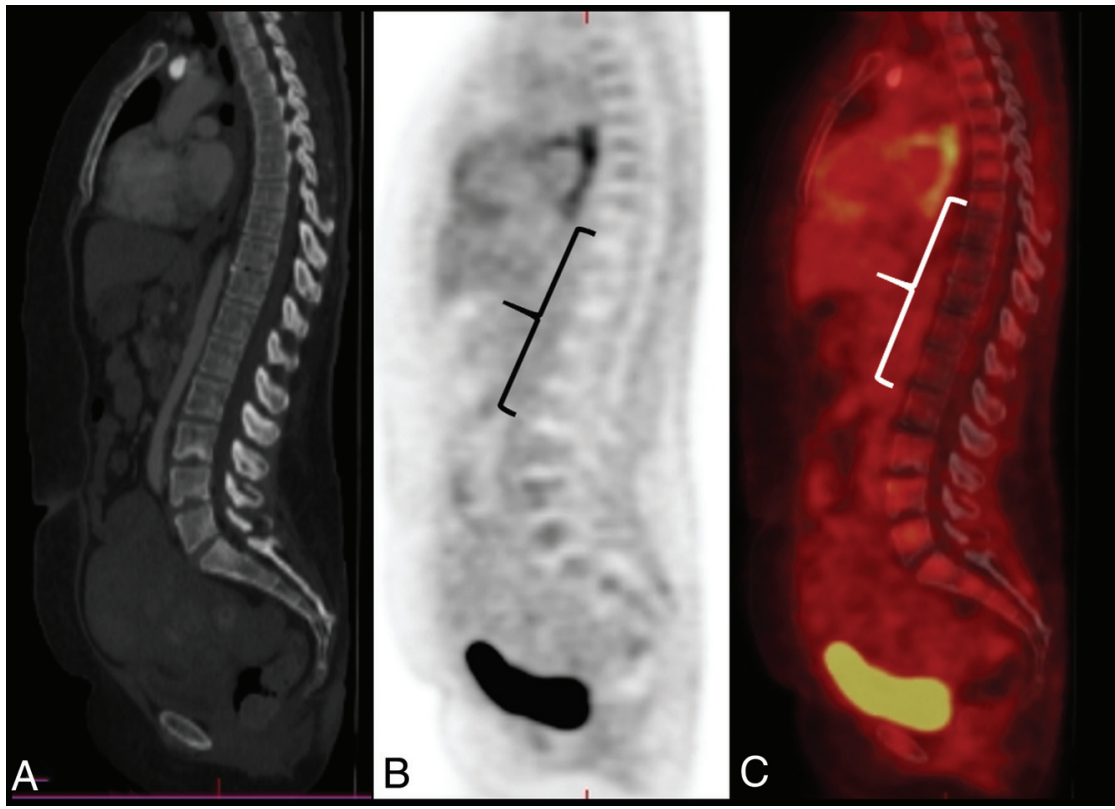

FIG 3. A 48-year-old man with B-cell lymphoma of the gastric fundus after radiation therapy. Sagittal CT (A), AC PET (B), and fused (C) images demonstrate a large photopenic segment (bracket) in the radiation field. Note the absence of a correlative abnormality on $\mathrm{CT}$ in this region. Fused indicates fused PET and CT image; AC, attenuation-corrected.

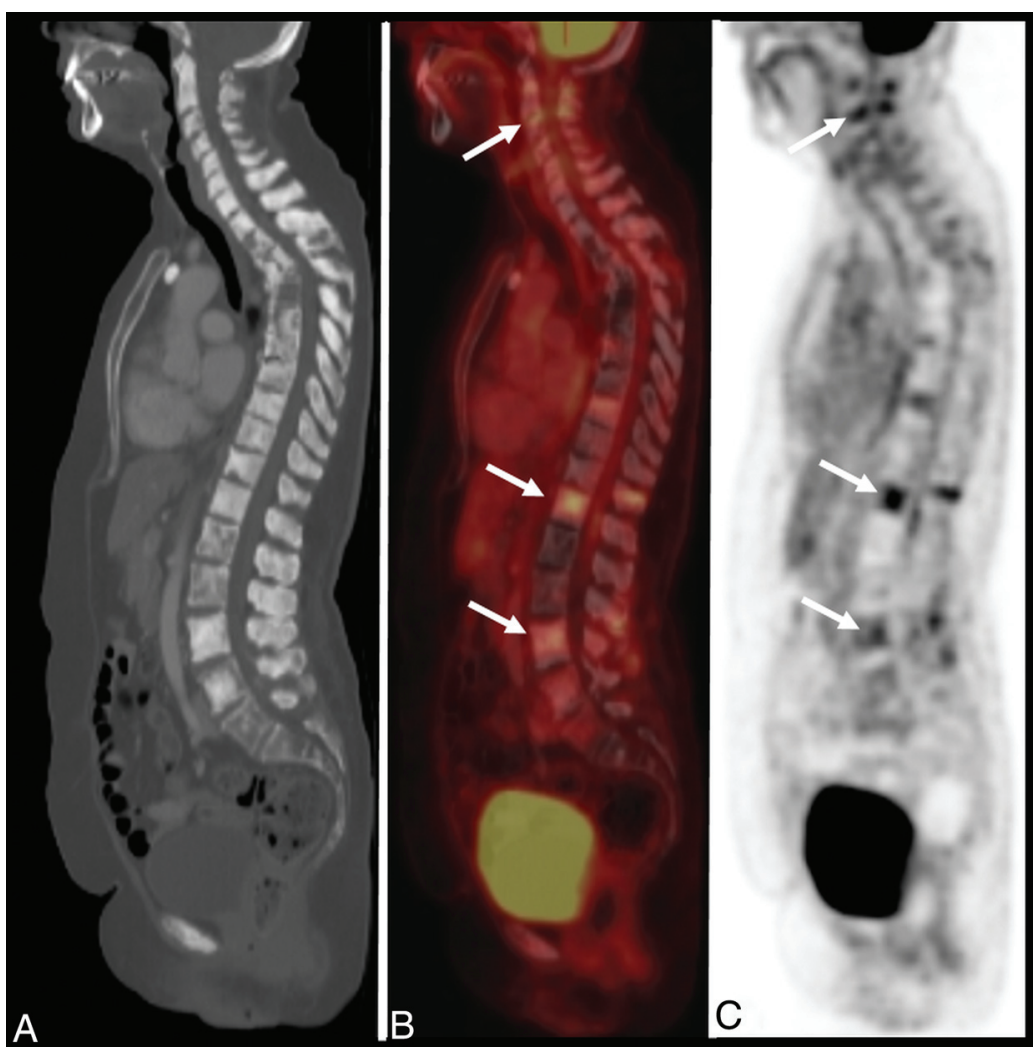

FIG 4. A 66-year-old woman with breast cancer. Sagittal CT (A), fused (B), and AC PET (C) images demonstrate extensive osseous metastases throughout the spine with a number of lesions demonstrating varying degrees of increased uptake (arrows). Heterogeneous radiotracer uptake is due to posttreatment changes. Absent radiotracer uptake suggests treated disease including in sclerotic vertebral bodies. This case demonstrates the superiority of PET/CT over conventional imaging in demonstrating a response to therapy. Fused indicates fused PET and CT image; AC, attenuation-corrected. often performed first during the initial staging and can offer valuable information, given its reliance on metabolic activity. $^{3}$

\section{Metastatic Disease}

Osseous. The spine is the third most common site of metastatic disease, following the lung and liver, with lung, breast, and prostate cancer the most commonly identified primary sites. ${ }^{15}$ The thoracic spine is the most commonly involved vertebral level, possibly due to the relatively increased degree of bone marrow volume to receive hematogenously spread metastatic deposits. ${ }^{2,16}\left[{ }^{18} \mathrm{~F}\right]$ FDG-PET is an important tool for the diagnosis of early osseous metastatic disease because increased glucose metabolism in neoplastic cells can become evident in even the earliest cases of bone marrow infiltration. ${ }^{15,17}$ $\left[{ }^{18} \mathrm{~F}\right]$ FDG-PET can demonstrate increased radiotracer uptake regardless of lesion type, either osteolytic or osteoblastic, though due to a multitude of factors including biochemical activity of these lesions, the degree of $\left[{ }^{18} \mathrm{~F}\right] \mathrm{FDG}$ uptake can be variable (Fig 4). ${ }^{15,18}$

PET/CT is superior to CT for the evaluation of treatment response, though imaging considerations in treatment response between PET/CT and MR imaging are more complicated, because specific disease processes may alter which is the most accurate method. While there are morphologic MR imaging findings indicative of both treatment response (eg, disappearance of focal lesions, decreased size/number of lesions) and disease progression (eg, increased number/size of lesions or evolution from focal to diffuse neoplastic infiltration), problems such as arrested resolution of abnormalities despite effective therapy that are thought to be due to bone sclerosis, marrow fibrosis, or necrosis as well as difficulty in evaluating disease activity on a scarred background and differences in MR imaging techniques limit morphologic assessment. ${ }^{19}$ Advanced MR imaging techniques such as perfusion and diffusion imaging can be used to supplement morphologic assessment through their assessment of tumor perfusion/permeability and cellular density/integrity, 


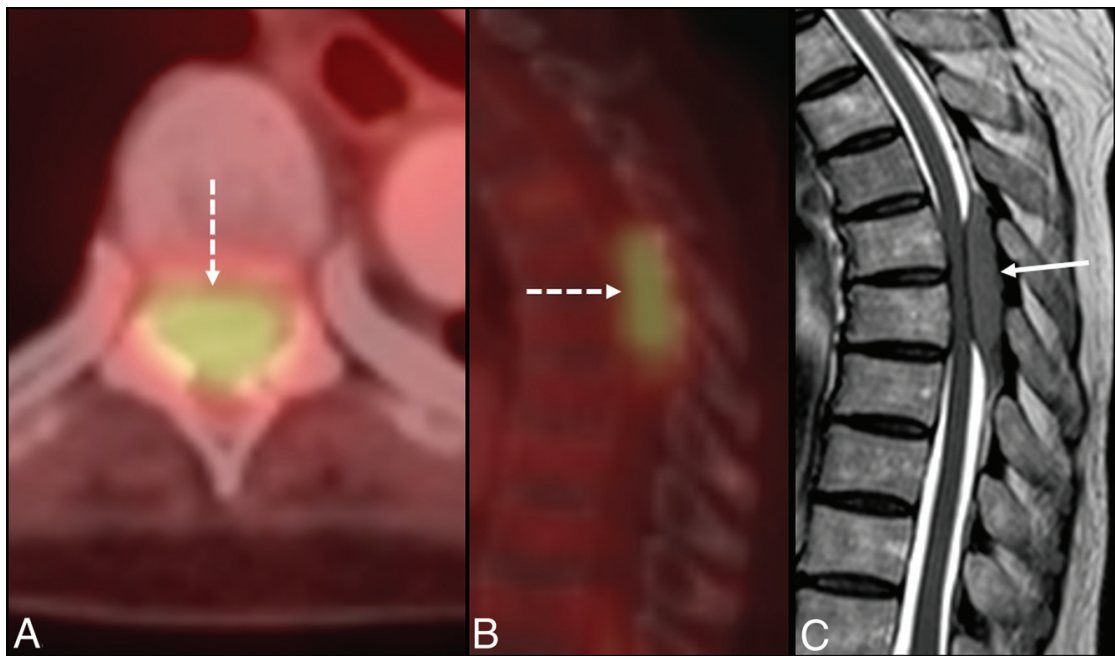

FIG 5. An 80 -year-old woman with mucosa-associated lymphatic tissue lymphoma. Axial fused $(A)$, sagittal fused $(B)$, and sagittal T2-weighted MR images (C) demonstrate an intensely hypermetabolic focus within the spinal column at T7-T8 (dashed arrow), which corresponds to a T2-isointense posterior epidural mass (solid arrow), which was found to be biopsy-proved metastatic lymphoma. Fused indicates fused PET and CT image.

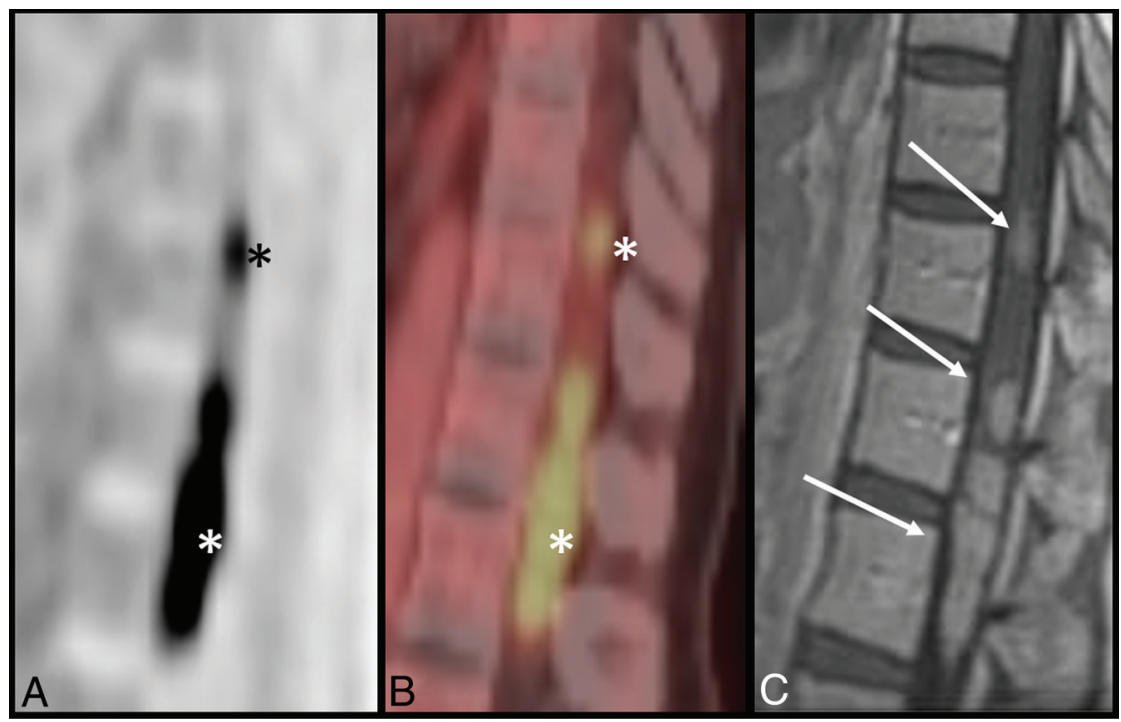

FIG 6. A 54-year-old woman with breast cancer. Sagittal AC (A) and fused (B) images show a linear segment of hypermetabolic activity (asterisk) in the thoracolumbar spinal column. This correlates with multiple enhancing intramedullary metastatic lesions (arrows) on corresponding sagittal T1-weighted postcontrast MR imaging (C). Fused indicates fused PET and CT image; AC, attenuation-corrected.

respectively. ${ }^{20}$ Like MR imaging, $\left[{ }^{18} \mathrm{~F}\right]$ FDG-PET also has issues when assessing only FDG-avid tumors as well as in the setting of flare reactions after G-CSF administration. Additionally, the choice of imaging technique, notably with the development of PET/MR imaging, should depend on the most accurate way to assess the primary lesion, especially in cases of osseous metastases. ${ }^{20}$

Epidural. With an incidence of up to 5\%-10\%, epidural metastatic disease can be seen in up to $40 \%$ of patients with pre-existing nonspinal osseous metastases. ${ }^{21}$ Prostate, breast, and lung cancer account for the most cases of epidural involvement. $^{21}$ Because thoracic spine involvement is most common, in approximately $60 \%$ of cases, epidural disease has the greatest likelihood of producing spinal cord injury. ${ }^{15,21,22}$ Epidural involvement can result from hematogenous and lymphatic dissemination or by contiguous extension from an adjacent vertebral body or through a neuroforamen. ${ }^{3,15}$ While MR imaging is superior to CT for evaluating epidural involvement, superimposed PET does improve the sensitivity of CT for detection, particularly when there is no associated adjacent osseous destruction (Fig 5). ${ }^{3}$ However, conventional PET alone is too limited in its spatial resolution, at about $4-5 \mathrm{~mm}$, to differentiate epidural from intradural disease, and while fused CT imaging can improve its sensitivity, suggested spinal canal disease should prompt analysis with MR imaging. ${ }^{23}$

Intramedullary. Intramedullary spinal cord metastasis (ISCM) is one of the rare forms of systemic metastatic disease, comprising between $1 \%$ and $3 \%$ of all patients with metastatic disease and up to $9 \%$ of those with central nervous system involvement. ${ }^{3}$ Approximately $50 \%$ of ISCMs arise from a primary lung cancer, followed by breast cancer as the second most common source. ${ }^{24,25}$ Up to one-third of these patients were shown to have concurrent brain metastases, and up to one-fourth had additional leptomeningeal carcinomatosis. ${ }^{25}$

Numerous studies have demonstrated an increased prevalence of thoracic spinal cord involvement. ${ }^{24}$ These lesions tend to show SUV uptake greater than the mediastinal blood pool, with one study showing an average $\mathrm{SUV}_{\text {max }}$ of $6.7 .^{26,27}$ The morphology of $\left[{ }^{18} \mathrm{~F}\right]$ FDG uptake on PET tends to demonstrate round hypermetabolic foci in most cases (Fig 6). In addition, most MR imaging-visible ISCMs tend to be seen on PET as well. ${ }^{3}$ MR imaging features that correlate with visibility on PET include a larger lesion enhancement area, a larger extent of T2 signal abnormality, and an increased ratio of T2 signal abnormality to contrast enhancement. ${ }^{26}$

Leptomeningeal. Leptomeningeal disease or leptomeningeal carcinomatosis involves the presence of metastatic cells within the subarachnoid space of the brain and spinal cord. Etiologies range from breast, small-cell lung cancer, melanoma, leukemia, and head and 


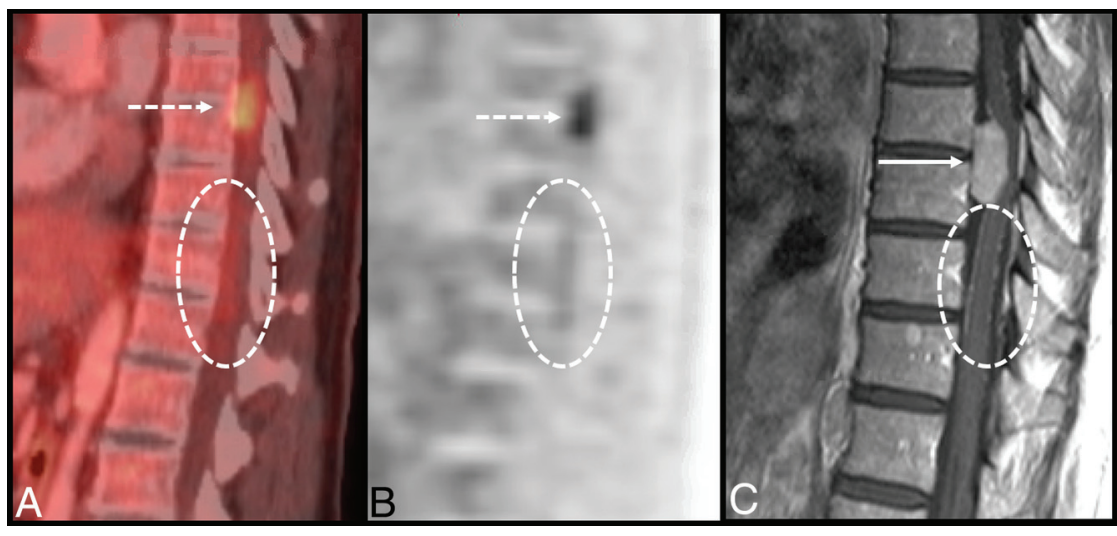

FIG 7. A 61-year-old man with chronic lymphocytic leukemia. Sagittal fused $(A), A C(B)$, and postcontrast T-weighted MR images $(C)$ demonstrate a hypermetabolic focus within the anterior thoracic spinal canal (dashed white arrow) corresponding to a solid, enhancing intradural extramedullary lesion (solid white arrow), which was found to be a schwannoma. There is additional subtle hypermetabolic uptake predominantly along the inferior thoracic cord (dashed circle), which demonstrates a "sugar-coating" pattern of enhancement on MR imaging, consistent with leptomeningeal spread of disease. Fused indicates fused PET and CT image; AC, attenuation-corrected. neck cancers, with up to $2 \%-5 \%$ of patients with breast cancer developing leptomeningeal disease. ${ }^{3,28,29}$ The pathogenesis is thought to occur by either hematogenous spread, extension through perivascular or perineural lymphatics, or direct extension from adjacent tumor. ${ }^{2,3}$ Although leptomeningeal disease is often undiagnosed or clinically silent, up to $98 \%$ of patients are symptomatic at the time of diagnosis. ${ }^{3,30}$

Leptomeningeal disease shows variable radiotracer uptake on $\left[{ }^{18} \mathrm{~F}\right] \mathrm{FDG}$ $\mathrm{PET}$, ranging from 2.8 to $11.1 \mathrm{SUV}_{\text {max }}$ in one study. ${ }^{30}$ The uptake pattern appears similar to the respective pattern of contrast enhancement on MR imaging (Fig 7). A classic example, the "bottle brush sign," demonstrates FDGavid disease within the lumbosacral spinal canal, extending through the sacral neural foramina. ${ }^{3}$ One limitation, how-

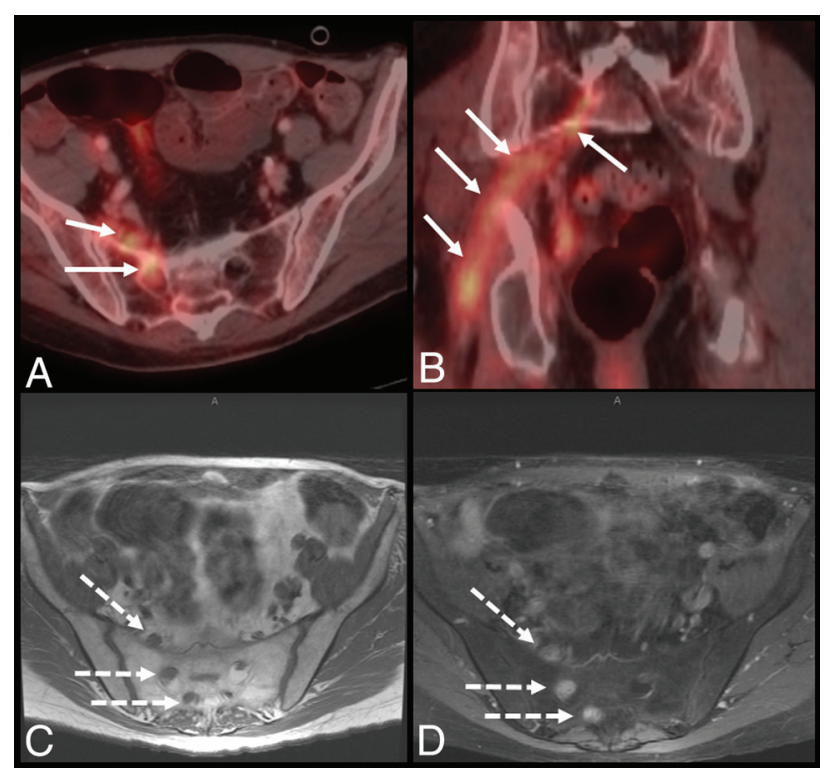

FIG 8. A 62-year-old man with penile cancer. Axial and coronal fused $(A$ and $B$ ) images demonstrate a long, nodular segment of radiotracer uptake within the right pelvis suspicious for perineural spread of metastases (white arrows). Corresponding axial T1-weighted precontrast and Tl-weighted fat-saturated postcontrast MR imaging ( $C$ and $D$ ) show nodular thickening and enhancement (dashed arrows) along the right sacral nerve roots. Fused indicates fused PET and CT image.

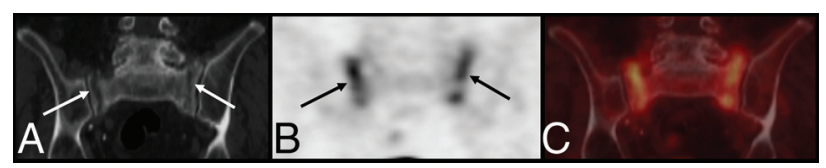

FIG 9. An 87-year-old woman with lung cancer. Coronal CT $(A),\left[{ }^{18} \mathrm{~F}\right]$ FDG-PET $(B)$, and PET/CT $(C)$ images at the sacroiliac level demonstrate bilateral linear lucencies through the sacral ala (white arrows), with corresponding linear radiotracer uptake (black arrows) compatible with insufficiency fractures. ever, is that patients with only thin linear or fine multinodular enhancement patterns on MR imaging demonstrated increased false-negative findings on PET studies. ${ }^{30}$ This is because most leptomeningeal disease is below the spatial resolution threshold of $\left[{ }^{18} \mathrm{~F}\right]$ FDG-PET. ${ }^{3}$

\section{Direct Extension}

Perineural. Perineural spread of malignancy, an under-recognized route of disease spread, describes the process of neoplastic dissemination along a nerve. This spread occurs along the pathway of least resistance, which is between the neural axon and surrounding perineural layer. ${ }^{31,32}$ The incidence of perineural tumor spread ranges from $2.5 \%$ to $5 \%$, with head and neck malignancies the most common cause. ${ }^{32,33}$

$\left[{ }^{18} \mathrm{~F}\right]$ FDG-PET demonstrates a sensitivity and specificity of $83 \%$ and $90 \%$, respectively, in the detection of perineural tumor spread. ${ }^{34}\left[{ }^{18} \mathrm{~F}\right] \mathrm{FDG}$-avid perineural lesions demonstrate linear or curvilinear increased uptake along the associated nerve in a discontinuous or nodular pattern, similar to MR imaging enhancement patterns (Fig 8). ${ }^{35}$ Perineural $\left[{ }^{18} \mathrm{~F}\right] \mathrm{FDG}$ uptake can be subtle, given the low spatial resolution of $\left[{ }^{18} \mathrm{~F}\right] \mathrm{FDG}-\mathrm{PET} .{ }^{35}$ Additionally, apart from the axial plane, one must use sagittal and coronal PET/CT images as well as MIP images for proper assessment. Limited analysis has shown that the mean $\mathrm{SUV}_{\text {max }}$ in patients with perineural metastatic spread is 7.1 (SD, 3.7). ${ }^{36}$ Secondary findings associated with perineural spread relate to eventual denervation and associated muscle atrophy, with $\left[{ }^{18} \mathrm{~F}\right] \mathrm{FDG}$-PET demonstrating increased uptake within the affected muscle in the acute phase followed by normalization in later stages and eventual decreased uptake in chronic atrophy. ${ }^{35}$ False-positives with $\left[{ }^{18} \mathrm{~F}\right]$ FDG-PET can be seen in cases of inflammation from prior radiation or surgery, especially within 1 month of surgery, with variable physiologic uptake in the adjacent musculature and lymphoid tissue as well as due to coregistration artifacts during PET and CT fusion. ${ }^{31,35}$ 


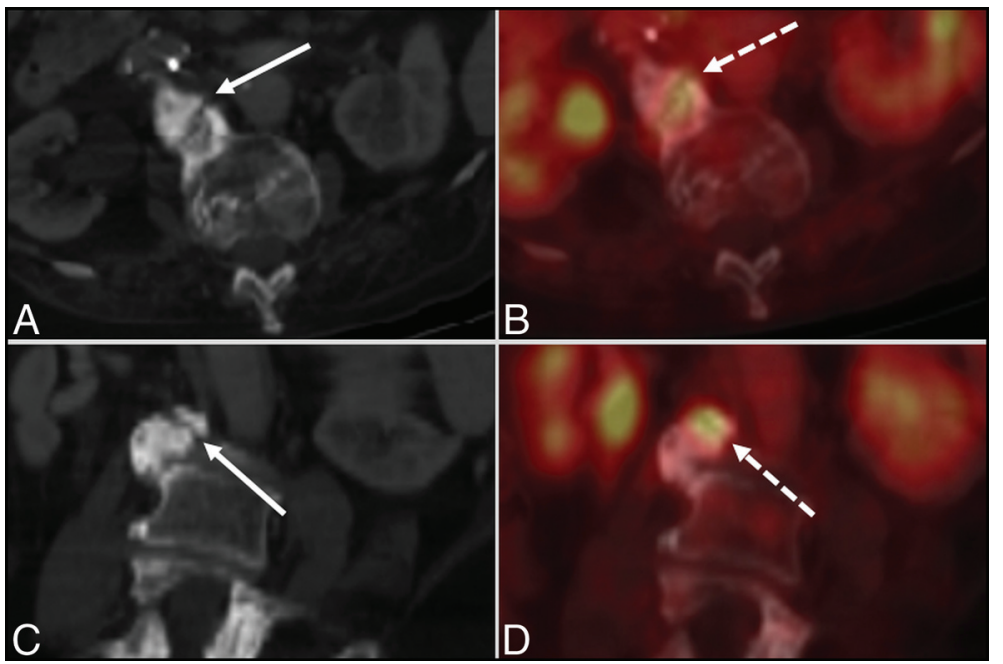

FIG 10. A 68-year-old woman with breast cancer. Axial $(A)$ and coronal $(C) C T$ and axial $(B)$ and coronal $(D)$ fused images demonstrate an intense focus of increased $\left[{ }^{18}\right.$ F]FDG uptake in the lumbar spine (dashed arrows) corresponding to a bulky osteophytic pseudoarthrosis on CT (solid arrows), which can mimic blastic osseous metastases. Fused indicates fused PET and CT image.
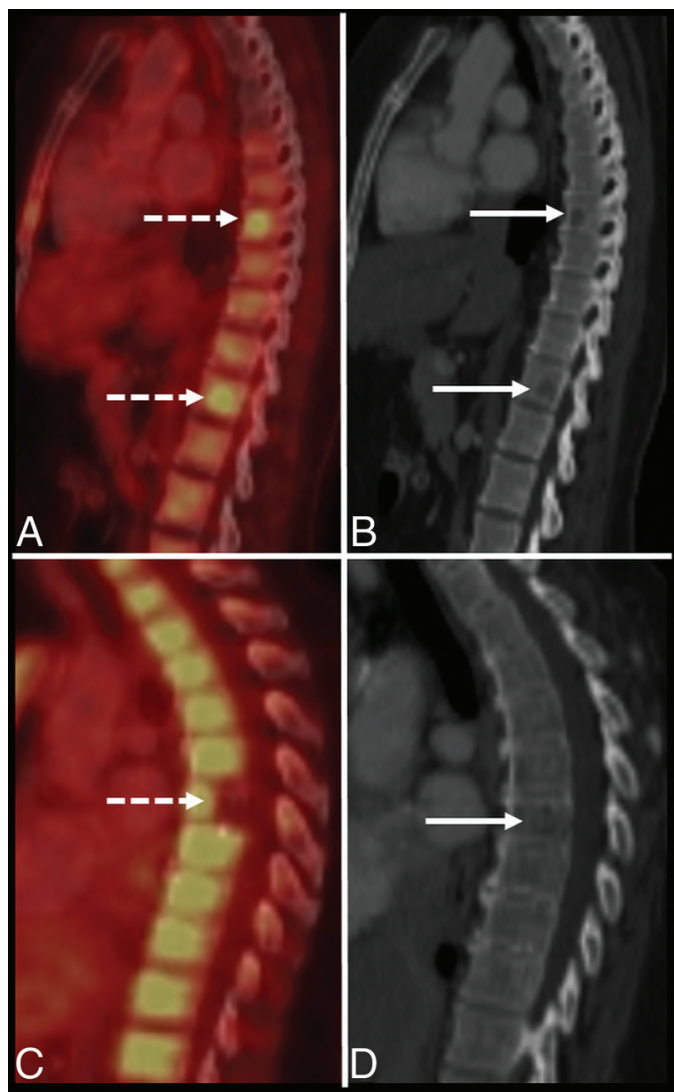

FIG 11. Upper row: A 50-year-old woman with multiple myeloma. Sagittal fused $(A)$ and $C T(B)$ images demonstrate foci of intensely increased FDG uptake (dashed arrows) in the thoracolumbar spine vertebral bodies, corresponding to lytic myelomatous lesions (solid arrows) on CT, which in the absence of a proper history, can appear as lytic osseous metastases. Lower row: A 62-year-old woman with breast cancer after recent chemotherapy. Sagittal fused image $(C)$ demonstrates an incidental photopenic lesion (dashed arrow) in the posterior T6 vertebral body corresponding to a hemangioma on CT (solid arrow). Fused indicates fused PET and CT image.
Direct Invasion. Direct invasion of tumor into the paraspinal soft tissues, vertebral bodies, and spinal canal is a frequent occurrence. Direct extension to the spinal column can be either from a primary site or a secondary site such as a local metastatic lymph node and is typically accompanied by a paraspinal soft-tissue mass, which is not seen with hematogenous metastases. ${ }^{2}$

\section{Nonmetastatic Disease of the Spine}

Trauma and Degeneration. Commonly encountered nonmetastatic spinal pathologies can pose challenges in patients in oncology undergoing $\left[{ }^{18} \mathrm{~F}\right] \mathrm{FDG}-\mathrm{PET}$ imaging. Specifically, traumatic injuries and age-related degenerative changes of the spine are two important areas of concern because osseous metastatic disease and fractures can present in a similar fashion. ${ }^{37}$ Sacral insufficiency fractures, in particular, can mimic pelvic osseous metastases; however, these tend to have more linear or $\mathrm{H}$-shaped pattern of uptake compared with the nodular patterns seen with metastatic disease (Fig 9). ${ }^{11,38}$ A key differentiator is the transient nature of $\left[{ }^{18} \mathrm{~F}\right] \mathrm{FDG}$ uptake in traumatic fractures, occurring due to the acute local inflammatory state, with no considerable uptake generally identified after 2-3 months. ${ }^{11,39}$

Degenerative and inflammatory arthropathies of the spine can also show mild-to-intense $\left[{ }^{18} \mathrm{~F}\right] \mathrm{FDG}$ avidity. In these cases, the degree of uptake is not necessarily linear in relation to the appearance of the degeneration but rather related to the degree of active inflammation. ${ }^{11,37,40}$ These findings most commonly are found near the vertebral body endplates and facet joints and include formation of synovial cysts, subchondral cysts, and osteophytosis, which can be difficult to delineate from lytic and blastic osseous metastases (Fig 10). ${ }^{11,37}$ Within the posterior elements, Baastrup disease, characterized by inflammatory changes involving the interspinous bursa and sclerosis of the spinous processes, can demonstrate mild-to-moderate $\left[{ }^{18} \mathrm{~F}\right] \mathrm{FDG}$ uptake and mimic posterior element metastases. ${ }^{38}$

Primary Osseous Lesions. Primary osseous pathology, while not always neoplastic, is commonly encountered on routine surveillance oncologic imaging. These lesions, notably multiple myeloma and hemangiomas, can mimic metastatic disease and are important considerations during the evaluation of osseous metastatic disease. Because myelomatous lesions are metabolically active, fused imaging with CT can demonstrate hypermetabolic lytic lesions, which can be easily confused with lytic metastases (Fig 11). ${ }^{41,42}$ Hemangiomas, on the other hand, typically present as incidental photopenic lesions on $\left[{ }^{18} \mathrm{~F}\right] \mathrm{FDG}-\mathrm{PET}$ (Fig 11), though occasionally internal hemorrhage and subsequent inflammatory changes of a vertebral hemangioma can demonstrate hypermetabolism. ${ }^{43-45}$ 


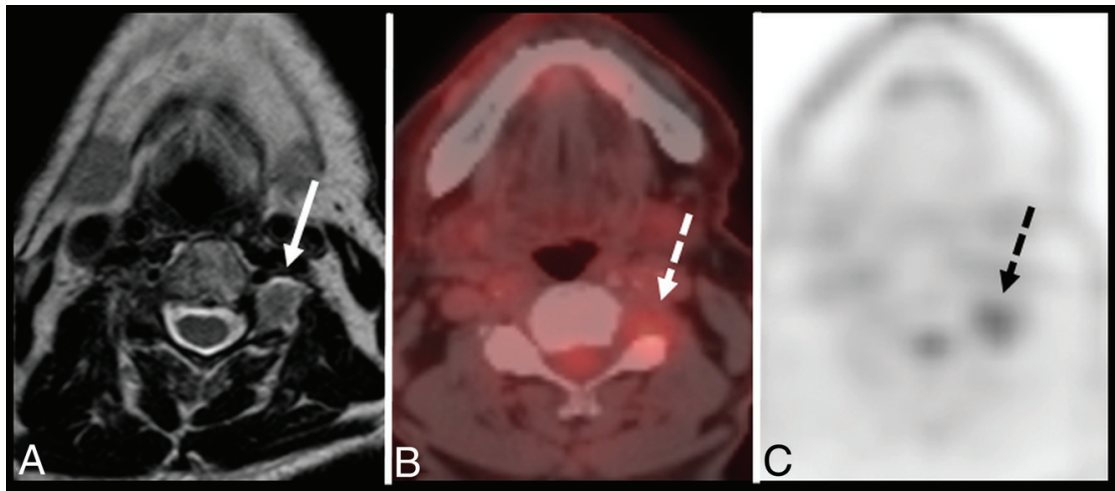

FIG 12. A 74-year-old man with thyroid cancer. Axial T2-weighted MR imaging (A), fused (B), and $\mathrm{AC}(C)$ images demonstrate mild increased $\left[{ }^{18} \mathrm{~F}\right] \mathrm{FDG}$ uptake (dashed arrows) within the paraspinal region at the C3-C4 level, appearing as a rounded soft-tissue density with neuroforaminal widening/remodeling and intermediate T2 signal on MR imaging (solid arrow). Findings corresponded to a schwannoma, which, in the setting of known primary malignancy, can mimic perineural metastasis. Fused indicates fused PET and CT image; AC, attenuation-corrected.

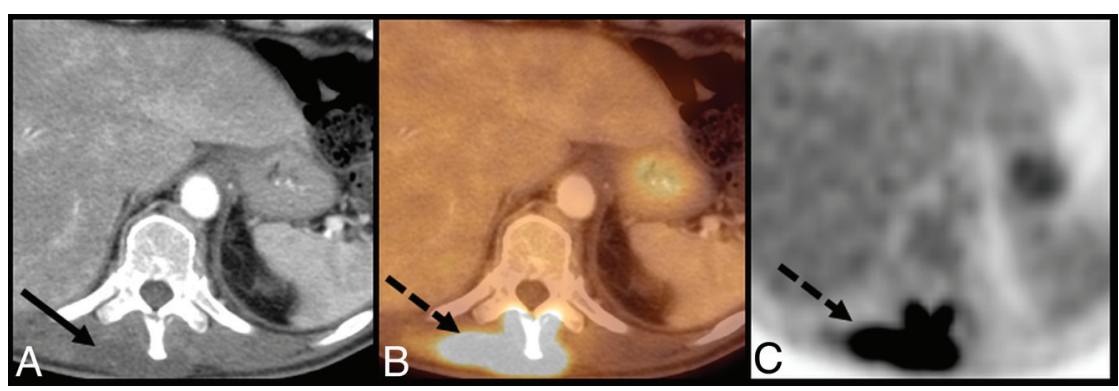

FIG 13. A 70-year-old man with rectal cancer. Axial $C T(A)$, fused (B), and $A C(C)$ images demonstrate intense hypermetabolic uptake (dashed arrows) in the paraspinal musculature of the mid and lower thoracic spine, which corresponds to a hypodense region of phlegmon/developing abscess on CT (solid arrow). Fluid cultures were positive for methicillin-resistant Staphylococcus aureus. Fused indicates fused PET and CT image; AC, attenuation-corrected.

FDG concentrations in adjacent tissues, below the reconstruction resolution, can underestimate true tumoral metabolic activity. ${ }^{50,51}$ In response, multiple partial volume correction methodologies are increasingly being developed to overcome this limitation, critical for the assessment of treatment response.

As calculation of total disease burden becomes of increasing clinical importance, alternatives in the method by which $\left[{ }^{18} \mathrm{~F}\right]$ FDG-PET data are analyzed has been studied. Particularly, total metabolic tumor volume and total lesion glycolysis have become more beneficial than typical SUVs regarding true tumor burden, risk stratification, and outcomes. $^{52,53}$ Of note, the calculation of total lesion glycolysis uses $\mathrm{SUV}_{\text {mean }}$ which, while affected by inter- and intraobserver variability, is less sensitive to image noise and reconstruction parameters and may make total lesion glycolysis more beneficial in assessing tumor burden compared with $\mathrm{SUV}_{\text {max }}{ }^{54-56}$ Although the time-consuming nature of manual quantification and correction makes use of total lesion glycolysis impractical for routine clinical practice, advancements in quantification software may make this limitation a moot point. $^{57,58}$

The potential applications of recently developed total-body $\mathrm{PET}$ imaging instruments have led to

Benign Neurogenic Lesions. Both primary malignant neoplasms of the spinal cord (eg, astrocytoma, ependymoma) as well as benign neurogenic lesions such as schwannomas can also mimic metastatic disease on PET. ${ }^{31}$ Schwannomas, which are the most common of the peripheral nerve sheath tumors, demonstrate variable $\left[{ }^{18} \mathrm{~F}\right] \mathrm{FDG}$ uptake and, in the setting of known malignancy, can appear similar to perineural spread of tumor, especially ones that demonstrate mild uptake (Fig 12). ${ }^{46,47}$

Infection. Given the overexpression of the glucose transport protein 1 subtype in macrophages, lymphocytes, and neutrophils, infectious processes can also demonstrate hypermetabolism on $\left[{ }^{18}\right.$ F]FDG-PET mimicking metastatic disease (Fig 13). ${ }^{11,48}$ Of particular note, tuberculous spondylitis can demonstrate multilevel subligamentous spread mimicking paravertebral lymphadenopathy in metastatic disease or lymphoma. ${ }^{49}$

\section{Additional Considerations}

Because the spatial resolution of $\left[{ }^{18} \mathrm{~F}\right] \mathrm{FDG}-\mathrm{PET}$ is limited compared with conventional imaging, true disease assessment can be considerably hindered by partial volume effects, in which $\left[{ }^{18} \mathrm{~F}\right]$ exciting advancements in clinical nuclear medicine and molecular imaging. With their increased axial FOV, these scanners use increased detection efficiency and scanner sensitivity to considerably improve the signal-to-noise ratio and temporal resolution, all while using a lower radiopharmaceutical dose, which can be specifically useful in determining the extent of disease in the spine and spinal cord. ${ }^{59,60}$ However, a major limitation for institutions outside of large research institutions remains the cost of these scanners, particularly the scintillation material, as well as data storage and processing concerns. ${ }^{61}$

\section{CONCLUSIONS}

Spinal involvement by malignancy, either by direct extension or distant metastases, is a relatively common occurrence in the workup and management of patients with cancer. While CT and MR imaging play important roles in the assessment of spinal metastatic disease, the importance and utility of $\left[{ }^{18} \mathrm{~F}\right] \mathrm{FDG}$-PET cannot be understated. ${ }^{3}$ Because PET and PET/CT are often used early in the oncologic work-up and for surveillance imaging, it is critical for radiologists to understand malignant and nonmalignant disease 
patterns and characteristics to make an accurate and useful diagnosis.

Disclosure forms provided by the authors are available with the full text and PDF of this article at www.ajnr.org.

\section{REFERENCES}

1. Alavi A, Hess S, Werner TJ, et al. An update on the unparalleled impact of FDG PET imaging on the day-to-day practice of medicine with emphasis on management of infectious/inflammatory disorders. Eur J Nucl Med Mol Imaging 2020;47:18-27 CrossRef Medline

2. Shah LM, Salzman KL. Imaging of spinal metastatic disease. Int $J$ Surg Oncol 2011;2011:769753 CrossRef Medline

3. Batouli A, Braun J, Singh K, et al. Diagnosis of non-osseous spinal metastatic disease: the role of PET/CT and PET/MRI. J Neurooncol 2018;138:221-30 CrossRef Medline

4. Bhatt G, Li XF, Jain A, et al. The normal variant (18)F FDG uptake in the lower thoracic spinal cord segments in cancer patients without CNS malignancy. Am J Nucl Med Mol Imaging 2013;3:317-25 Medline

5. Buyukdereli G, Kara E, Guler M, et al. Evaluation of visible physiological F-18 FDG uptake patterns in spinal cord on PET/CT. Neurosurgery Quarterly 2015;25:403-06 CrossRef

6. Do BH, Mari C, Tseng JR, et al. Pattern of 18F-FDG uptake in the spinal cord in patients with non-central nervous system malignancy. Spine (Phila Pa 1976) 2011;36:E1395-401 CrossRef Medline

7. Amin A, Rosenbaum SJ, Bockisch A. Physiological ${ }^{18}$ F-FDG uptake by the spinal cord: is it a point of consideration for cancer patients? J Neurooncol May 2012;107:609-15 CrossRef Medline

8. Shen G, Liang M, Su M, et al. Physiological uptake of 18F-FDG in the vertebral bone marrow in healthy adults on PET/CT imaging. Acta Radiol 2018;59:1487-93 CrossRef Medline

9. Su M, Xu D, Li F, et al. Pattern of variable physiological 18F-FDG uptake at various levels in the spine on 18F-FDG PET/CT. J Nucl Med 2016;57(Suppl 2):1756

10. Kazama T, Faria SC, Varavithya V, et al. FDG PET in the evaluation of treatment for lymphoma: clinical usefulness and pitfalls. Radiographics 2005;25:191-207 CrossRef Medline

11. Lin EC, Alavi A. PET and PET/CT: A Clinical Guide. 2nd ed. Thieme; 2009

12. Hanaoka K, Hosono M, Usami K, et al. Fluorodeoxyglucose uptake in the bone marrow after granulocyte colony-stimulating factor administration in patients with non-Hodgkin's lymphoma. Nucl Med Commun 2011;32:678-83 CrossRef Medline

13. Ulaner GA, Lyall A. Identifying and distinguishing treatment effects and complications from malignancy at FDG PET/CT. Radiographics 2013;33:1817-34 CrossRef Medline

14. Kesner AL, Lau VK, Speiser M, et al. Time-course of effects of external beam radiation on [18F]FDG uptake in healthy tissue and bone marrow. J Appl Clin Med Phys 2008;9:147-56 CrossRef Medline

15. Metser U, Lerman H, Blank A, et al. Malignant involvement of the spine: assessment by 18F-FDG PET/CT. J Nucl Med 2004;45:279-84 Medline

16. Rose PS, Buchowski JM. Metastatic disease in the thoracic and lumbar spine: evaluation and management. J Am Acad Orthop Surg 2011;19:37-48 CrossRef Medline

17. Ali SA, Ibrahim Y, Elkhalek A. Added value of combined 18F-FDG PET/CT for detection of osseous metastases in cancer patients. Egypt J Radiol Nucl Med 2016;47:453-58 CrossRef

18. Uchida K, Nakajima H, Miyazaki T, et al. (18)F-FDG PET/CT for diagnosis of osteosclerotic and osteolytic vertebral metastatic lesions: comparison with bone scintigraphy. Asian Spine J 2013;7:96-103 CrossRef Medline

19. Woolf DK, Padhani AR, Makris A. Assessing response to treatment of bone metastases from breast cancer: what should be the standard of care? Ann Oncol 2015;26:1048-57 CrossRef Medline
20. Lecouvet FE, Larbi A, Pasoglou V, et al. MRI for response assessment in metastatic bone disease. Eur Radiol 2013;23:1986-97 CrossRef Medline

21. Mavrogenis AF, Pneumaticos S, Sapkas GS, et al. Metastatic epidural spinal cord compression. Orthopedics 2009;32:431-39 CrossRef Medline

22. Ho L, Valenzuela D, Negahban A, et al. Primary spinal epidural non-Hodgkin lymphoma demonstrated by FDG PET/CT. Clin Nucl Med 2010;35:487-89 CrossRef Medline

23. Watakabe $\mathrm{T}$, Toya $\mathrm{R}$, Saito $\mathrm{T}$, et al. High spatial resolution digital positron emission tomography images with dedicated source-tobackground algorithm for radiotherapy planning. Anticancer Res 2020;40:2567-72 CrossRef Medline

24. Rykken JB, Diehn FE, Hunt $\mathrm{CH}$, et al. Intramedullary spinal cord metastases: MRI and relevant clinical features from a 13-year institutional case series. AJNR Am J Neuroradiol 2013;34:2043-49 CrossRef Medline

25. Pellegrini D, Quezel MA, Bruetman JE. Intramedullary spinal cord metastasis. Arch Neurol 2009;66:1422 CrossRef Medline

26. Mostardi PM, Diehn FE, Rykken JB, et al. Intramedullary spinal cord metastases: visibility on PET and correlation with MRI features. AJNR Am J Neuroradiol 2014;35:196-201 CrossRef Medline

27. Tomura $\mathrm{N}$, Ito $\mathrm{Y}$, Matsuoka $\mathrm{H}$, et al. PET findings of intramedullary tumors of the spinal cord using $[18 \mathrm{~F}]$ FDG and $[11 \mathrm{C}]$ methionine. AJNR Am J Neuroradiol 2013;34:1278-83 CrossRef Medline

28. Farin A, Aryan HE, Abshire BB. Thymoma metastatic to the extradural spine. J Clin Neurosci 2005;12:824-27 CrossRef Medline

29. Shah S, Rangarajan V, Purandare N, et al. 18F-FDG uptakes in leptomeningeal metastases from carcinoma of the breast on a positron emission tomography/computerized tomography study. Indian J Cancer 2007;44:115-18 CrossRef Medline

30. Papasozomenos H, Guha-Thakurta N, Mayer RR, et al. Association between (18)F-FDG PET/CT and MRI appearance of spinal leptomeningeal disease before and after treatment at a tertiary referral center. J Solid Tumors 2016;6:1-8 CrossRef Medline

31. Paes FM, Singer AD, Checkver AN, et al. Perineural spread in head and neck malignancies: clinical significance and evaluation with 18F-FDG PET/CT. Radiographics 2013;33:1717-36 CrossRef Medline

32. Liebig C, Ayala G, Wilks JA, et al. Perineural invasion in cancer: a review of the literature. Cancer 2009;115:3379-91 CrossRef Medline

33. Maroldi R, Farina D, Borghesi A, et al. Perineural tumor spread. Neuroimaging Clin N Am 2008;18:413-29 CrossRef Medline

34. Sherif M, Dawoud M, Nagy H, et al. Diagnostic accuracy of 18-F FDG PET/CT in evaluation of malignant neuronal involvement in neurologically manifested cancer patients. Egypt J Radiol Nucl Med 2018;49:453-60 CrossRef

35. Lee H, Lazor JW, Assadsangabi R, et al. An imager's guide to perineural tumor spread in head and neck cancers: radiologic footprints on (18)F-FDG PET, with CT and MRI correlates. J Nucl Med 2019;60:304-11 CrossRef Medline

36. Kirchner J, Schaarschmidt BM, Sauerwein W, et al. (18) F-FDG PET/ MRI vs MRI in patients with recurrent adenoid cystic carcinoma. Head Neck 2019;41:170-76 CrossRef Medline

37. Costelloe CM, Murphy WA Jr, Chasen BA. Musculoskeletal pitfalls in 18F-FDG PET/CT: pictorial review. AJR Am J Roentgenol 2009;193:WS1-13 CrossRef Medline

38. White ML, Johnson GB, Howe BM, et al. Spectrum of benign articular and periarticular findings at FDG PET/CT. Radiographics 2016;36:824-39 CrossRef Medline

39. Zhuang H, Sam JW, Chacko TK, et al. Rapid normalization of osseous FDG uptake following traumatic or surgical fractures. Eur J Nucl Med Mol Imaging 2003;30:1096-103 CrossRef Medline

40. Rosen RS, Fayad L, Wahl RL. Increased 18F-FDG uptake in degenerative disease of the spine: characterization with 18F-FDG PET/ CT. J Nucl Med 2006;47:1274-80 Medline

41. Bredella MA, Steinbach L, Caputo G, et al. Value of FDG PET in the assessment of patients with multiple myeloma. AJR Am J Roentgenol 2005;184:1199-204 CrossRef Medline 
42. Zhang H, Lv J, Lv C, et al. Presentation of multiple myeloma mimicking bone metastasis from colon adenocarcinoma: a case report and literature review. Mol Clin Oncol 2016;4:31-34 CrossRef Medline

43. Bybel B, Raja S. Vertebral hemangiomas on FDG PET scan. Clin Nucl Med 2003;28:522-23 CrossRef Medline

44. Solav SV, Savale SV, Patil AM. False-positive FDG PET CT scan in vertebral hemangioma. Asia Ocean J Nucl Med Biol 2019;7:95-98 CrossRef Medline

45. Nakayama M, Okizaki A, Ishitoya S, et al. "Hot" vertebra on (18)FFDG PET scan: a case of vertebral hemangioma. Clin Nucl Med 2012;37:1190-93 CrossRef Medline

46. Boré P, Descourt R, Ollivier L, et al. False positive 18F-FDG positron emission tomography findings in schwannoma-a caution for reporting physicians. Front Med (Lausanne) 2018;5:275 CrossRef Medline

47. Beaulieu S, Rubin B, Djang D, et al. Positron emission tomography of schwannomas: emphasizing its potential in preoperative planning. AJR Am J Roentgenol 2004;182:971-74 CrossRef Medline

48. Gemmel F, Rijk PC, Collins JM, et al. Expanding role of 18F-fluoroD-deoxyglucose PET and PET/CT in spinal infections. Eur Spine J 2010;19:540-51 CrossRef Medline

49. Burrill J, Williams CJ, Bain G, et al. Tuberculosis: a radiologic review. Radiographics 2007;27:1255-73 CrossRef Medline

50. Hoetjes NJ, van Velden FH, Hoekstra OS, et al. Partial volume correction strategies for quantitative FDG PET in oncology. Eur J Nucl Med Mol Imaging 2010;37:1679-87 CrossRef Medline

51. Bai B, Bading J, Conti PS. Tumor quantification in clinical positron emission tomography. Theranostics 2013;3:787-801 CrossRef Medline

52. Chen S, He K, Feng F, et al. Metabolic tumor burden on baseline (18)F-FDG PET/CT improves risk stratification in pediatric patients with mature B-cell lymphoma. Eur J Nucl Med $\mathrm{Mol}$ Imaging 2019;46:1830-39 CrossRef Medline

53. Vallius T, Hynninen J, Kemppainen J, et al. (18)F-FDG PET/CT based total metabolic tumor volume change during neoadjuvant chemotherapy predicts outcome in advanced epithelial ovarian cancer. Eur J Nucl Med Mol Imaging 2018;45:1224-32 CrossRef Medline

54. Rogasch JM, Steffen IG, Hofheinz F, et al. The association of tumorto-background ratios and SUVmax deviations related to point spread function and time-of-flight F18-FDG PET/CT reconstruction in colorectal liver metastases. EJNMMI Res 2015;5:31 CrossRef Medline

55. Ziai P, Hayeri MR, Salei A, et al. Role of optimal quantification of FDG PET imaging in the clinical practice of radiology. Radiographics 2016;36:481-96 CrossRef Medline

56. Burger IA, Huser DM, Burger C, et al. Repeatability of FDG quantification in tumor imaging: averaged SUVs are superior to SUVmax. Nucl Med Biol 2012;39:666-70 CrossRef Medline

57. Brito AE, Mourato F, Santos A, et al. Validation of the semiautomatic quantification of (18)F-fluoride PET/CT whole-body skeletal tumor burden. J Nucl Med Technol Technol 2018;46:378-33 CrossRef Medline

58. Froelich JW, Salavati A. Artificial intelligence in PET/CT is about to make whole-body tumor burden measurements a clinical reality. Radiology 2020;294:453-54 CrossRef Medline

59. Tan H, Gu Y, Yu H, et al. Total-body PET/CT: current applications and future perspectives. AJR Am J Roentgenol 2020;215:325-37 CrossRef Medline

60. Badawi RD, Shi H, Hu P, et al. First human imaging studies with the EXPLORER total-body PET scanner. J Nucl Med 2019;60:299303 CrossRef Medline

61. Vandenberghe S, Moskal P, Karp JS. State of the art in total body PET. EJNMMI Phys 2020;7:35 CrossRef Medline 